\title{
Os principais hidrônimos da cidade de Pires do Rio-GO e suas
}

\section{motivações de nomeação / The main hydroxymes of the city of Pires do}

\author{
Rio-GO and their motivations for nomination
}

\author{
Cleber Cezar da Silva*
}

\begin{abstract}
RESUMO
O objetivo desta pesquisa centra-se em analisar e descrever os principais hidrônimos de Pires do Rio de forma etimológica/morfológica e semântica-motivacional, identificando as relações entre esses designativos de lugares e respectivos fatores contextuais, língua, cultura e ambiente que subjazem a motivação toponímica. Esse estudo é parte de nossa pesquisa de mestrado na área de Estudos da Linguagem, Universidade Federal de Goiás (UFG), Regional Catalão. A metodologia da pesquisa pautase na onomasiologia, a qual se constitui do estudo das designações e tem como propósito analisar os diversos nomes atribuídos a um conceito. Em relação à toponímia, os aspectos históricos são reveladores do que subjaz à nomeação dos lugares. A toponímia constitui a área da Linguística e as bases teóricas que sustentam esta pesquisa são: Andrade (2010), Dick (1990, 1996, 2004, 2006), Pereira (2009) Siqueira (2012, 2015), Silva (2017) e Sousa (2008). Relacionar língua, cultura e ambiente é fundamental, pois a língua recorta a realidade a sua maneira, assim buscamos em Couto (2007, 2015), Coseriu (1982), Saussure (2008) e Sapir $(1969,1980)$ evidenciar essas relações. Os dicionários são específicos para a análise dos dados e preenchimento das fichas lexicográfico-toponímica, para tanto, Cunha (2010), Sampaio (1901, 1928) e Tibiriça (1985) sustentam a análise da origem dos hidrônimos. Por fim, os fatores motivacionais no processo de nomeação dos hidrônimos revelam a influência do denominar sobre o local nomeado por meio da identificação de fatos sociais, culturais, históricos, bem como outras motivações de diferentes naturezas e suas relações com a língua, cultura e ambiente.
\end{abstract}

PALAVRAS-CHAVE: Toponímia; Língua; Cultura; Hidrônimos; Pires do Rio.

\section{ABSTRACT}

The aim of the present research is to analyze and describe the main hydronyms in Pires da Costa based on an etymological/morphological and semantical-motivational approach. It will be done by identifying the relationships between designations given to these places and their respective contextual, linguistic, cultural and environmental factors, which depend on the toponymic motivation. This study is part of our master's degree research in Language Studies, which was developed at Universidade Federal de Goiás (UFG), Catalão Region. Research methodology was based on onomasiology, which means the study about designations and aims at assessing the different names given to a concept. Historical aspects of toponymy are quite clarifying when it comes to names given to places. Toponymy is part of Linguistics fields. The theoretical basis supporting the present research comprises Andrade (2010), Dick (1990, 1996, 2004, 2006), Pereira (2009) Siqueira (2012, 2015), Silva (2017) and Sousa (2008). Relating language, culture and environment is essential, since language draws reality as it pleases; thus, Couto (2007, 2015), Coseriu (1982), Saussure (2008) and Sapir (1969, 1980) were the references to evidence these relationships. Dictionaries are specific instruments to analyze data and to fill out lexicographic-toponymic files; therefore, Cunha (2010), Sampaio (1901, 1928) and Tibiriça (1985) advocate for the analysis of the origin of hydronyms. Finally, motivation factors associated with hydronym-designation processes evidence nominators' influence over a place, which is named based on the identification of social, cultural and historical factors, as well as on other motivations of different nature, and on their association with language, culture and environment.

KEYWORDS: Toponymy; Language; Culture; Hydroxymes; Pires do Rio County.

\footnotetext{
* Doutorando em Linguística, Universidade de Brasília - UnB. Brasília, Distrito Federal, Brasil. Professor da área de Línguas (português/espanhol) do Instituto Federal Goiano - Campus Urutaí, Urutaí, Goiás, Brasil. cleber.silva@ifgoiano.edu.br
} 


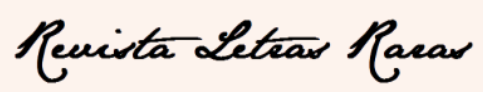

ISSN: 2317-2347 - v. 8, n. 1 (2019)

\section{Introdução}

Ao dar nome a seres e objetos, o homem também os categoriza, já que é o ato de nomear que dá existência a algo ou a alguém. É por meio do nome que há identificação e, principalmente, a diferenciação dos seres e dos objetos. No ato da nomeação diversos aspectos extralinguísticos podem influenciar o nomeador, isso pode caracterizar especificamente a motivação que subjaz a qualquer signo linguístico em função toponímica.

A motivação, por sua vez, é reveladora de inúmeros aspectos que estão na base da inter-relação língua, cultura e ambiente, pois o nome próprio de lugar como fato da língua, identifica e guarda uma significação precisa e oriunda de aspectos físicos ou culturais. Desta forma, busca-se mediante o estudo dos designativos dos cursos d'água da cidade de Pires do Rio-GO, descrever essa relação (língua, cultura e ambiente). Entende-se assim, que um rio, um riacho, um ribeirão, um córrego são lugares que, uma vez nomeados, passam a carregar as inúmeras memórias do lugar (SILVA, 2017).

Em decorrência disso, abrem-se possibilidades de inter-relacionar áreas do saber humano com vista a estabelecer algum vínculo epistemológico a fim de proporcionar novos olhares sobre um objeto já descrito e analisado por outra área do conhecimento a geografia, mas restrito a um único nível de análise linguística. Isso leva a considerar os aspectos da linguagem dentro de uma visão interdisciplinar, que pode trazer, entre tantas contribuições, o fato de entendê-los na totalidade, como em uma rede de relações. Em outras palavras, oferece a possibilidade de analisar os fatos linguísticos de maneira holística, visto que os fatores envolvidos na interação devem ser concebidos como um todo formado por componentes a se relacionarem entre si.

Os estudos toponímicos têm sua base na Linguística e objetivam analisar as ligações existentes entre o nome e a coisa nomeada, ou seja, os fatores motivacionais, cujo topônimo torna-se motivado. Sabemos que o nomeador no processo da lexicalização (nomeação) só irá atribuir características que, de alguma forma, tenha aproximação com seu contexto atual.

Neste artigo, analisamos três hidrônimos - rio Corumbá, rio Piracanjuba e rio do Peixe - os mais importantes para a cidade de Pires do Rio-GO em relação à calda 


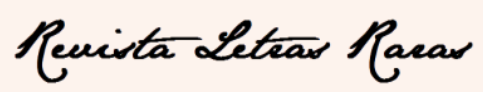

ISSN: $2317-2347$ - v. 8, n. 1 (2019)

d'água e às atividades de sustento e trabalho para as zonas rural e urbana. $\mathrm{Na}$ perspectiva onomasiológica, o método se constitui do estudo das designações com o intuito de estudar os diversos nomes atribuídos a um conceito. O topônimo carrega fatos históricos e culturais de uma determinada comunidade, podendo revelar a inter-relação de língua, cultura e ambiente.

Ao analisar os hidrônimos da cidade de Pires do Rio-GO, é perceptível que eles são caracterizados pelas relações de língua, cultura e ambiente, revelando aspectos consideráveis acerca da toponímia local e o próprio nomeador designou os referidos hidrônimos.

\section{A nomeação e a categorização do topônimo via língua e cultura}

O nome é a parte que caracteriza a existência de algo ou alguém. Sem a especificidade do nome, o objeto ou a pessoa não é identificada. Aliás, em muitas situações, o nome consolida a existência do objeto, que passa a "existir" como tal em decorrência de ter um nome, ou seja, o falante pode perceber no mundo apenas aquilo que conhece pelo nome.

O nome está presente em todas as esferas do desenvolvimento da humanidade; ele é parte constitutiva do próprio indivíduo, que se reconhece e se afirma face ao nome que carrega; é também o nome que lhe rompe o anonimato e confere, de certa forma, uma identidade.

Segundo Silva (2000), é o nome que diferencia os seres e os objetos do mundo. Identidade e diferença ocorrem simultaneamente como produto de um mesmo processo, o da identificação. Pode-se afirmar que, depois de nomeado, o objeto passa a ser identificado pelas diferenças que possui em relação àquilo que não é, ou melhor, é diferenciado face aos demais elementos do mundo extralinguístico, conferindo-lhe existência. Ter um nome é existir, tornar-se conhecido e ser reconhecido como elemento cultural importante para a continuidade de uma população como um dos milhares de traços que a caracteriza e, desta forma, "o processo de nomeação é uma forma pela qual a sociedade cria os seus membros à sua imagem" (CABRAL, 2007, p. 85). 


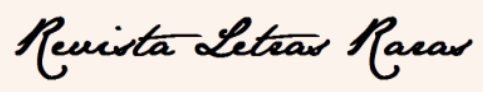

ISSN: $2317-2347$ - v. 8, n. 1 (2019)

A nomeação é uma atividade significativa para o ser humano e se constitui de uma ação complementar do modo como determinada população entende o meio em que vive, pois,

\begin{abstract}
Apreensão/compreensão e transmissão/participação de um dado qualquer do saber humano são atuantes de uma mesma e complexa evidência relacional - $\mathrm{o}$ ato comunicativo - que corporifica, em sua expressividade, um aglomerado de situações línguo-sócio-psíquicas. Nele está manifesto, ainda que de modo implícito, o registro pelo qual se concretizou a "assimilação do mundo" através do código de linguagem vivenciado por determinada comunidade linguística (DICK, 1990, p. 29).
\end{abstract}

Visto isso, não é equivocado asseverar que o nome corporifica aquilo que determinada comunidade assimilou de seu meio circundante por meio das relações estabelecidas entre a língua, a qual possibilita a representação daquilo que foi evidenciado, bem como as impressões sociopsíquicas oriundas dos objetos do mundo que se tornaram salientes aos olhos do nomeador. Então, recebe um nome tudo aquilo que, de uma forma ou de outra, tornou-se um item da cultura, seja um acidente físiconatural (um rio, uma espécie botânica) ou um item criado culturalmente. Em todas as sociedades há referência aos nomes e, consequentemente, à ação de nomear. Muitas vezes, essa atividade humana é revestida de mitos e rituais, conferindo ao nome poderes mágicos ou sobre-humanos.

Nesse processo de nomeação, categorização e motivação nos estudos na área da Onomástica, mais precisamente na subárea dos Estudos Toponímicos - temática de nossa pesquisa -, não tem como desvencilhar língua e cultura. Para Sapir-Whorf (19691971), a língua retrata o mundo e a realidade social à sua volta, expressos por categorias lexicais, como os topônimos.

Convém rever alguns conceitos que remetem ao caráter eminentemente social da língua, mais condizente com o recorte epistemológico feito por Saussure (2008, p. 17):

Mas o que é a língua? Para nós, ela não se confunde com a linguagem; é somente uma parte determinada, essencial dela, indubitavelmente. É, ao mesmo tempo, um produto social da faculdade de linguagem e um conjunto de convenções necessárias, adotadas pelo corpo social para permitir o exercício dessa faculdade nos indivíduos. Tomada em seu todo, a linguagem é multiforme e heteróclita; o cavaleiro de diferentes domínios, ao mesmo tempo física, fisiológica e psíquica, ela pertence 


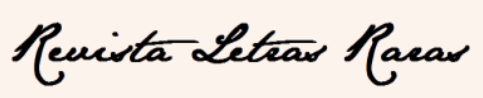

ISSN: 2317-2347 - v. 8, n. 1 (2019)

além disso ao domínio individual e ao domínio social; não se deixa classificar em nenhuma categoria de fatos humanos, pois não se sabe como inferir sua unidade.

A língua no contexto sócio-histórico-cultural nada mais é que o resultado de um processo histórico, um produto revelador da cultura de uma dada comunidade (CÂMARA JR, 1955). Nessas bases, inter-relacionar língua e cultura é justificar que estão intrinsecamente interligadas, pois a língua revela a visão de mundo e é também a manifestação de uma cultura, a qual dá suporte a língua que também é suporte da cultura.

Em seus estudos, Paula (2007) menciona que a língua é um metassistema, ela "não é só objeto; ela é, nas relações sociais mais diversamente possíveis, também instrumento de investigação distinto que ajuda a entender os outros sistemas sociais" (PAULA, 2007, p. 90). Nesse contexto, é possível evidenciar que por meio da língua são reeditadas e reconfiguradas as práticas culturais de uma dada comunidade.

Sapir (1980) ressalta a estreita ligação entre língua e cultura, afirmando que:

Toda língua tem uma sede. O povo que a fala, pertence a uma raça (ou a certo número de raças), isto é, a um grupo de homens que se destaca de outros grupos por caracteres físicos. Por outro lado, a língua não existe isolada de uma cultura, isto é, de um conjunto socialmente herdado por práticas e crenças que determinam a trama das nossas vidas" (SAPIR, 1980, p. 165).

Nesta perspectiva, reafirmando que língua se difere de linguagem, mas se entrecruza com ela ou dela faz parte e a considerando um dos fatores de identidade de um povo, a qual não existe isolada da cultura, é que se torna objeto de estudos envolvendo fatores sócio-histórico-culturais das comunidades.

Sapir (1969, p. 33) nos revela que "toda língua está de tal modo construída, que diante de tudo que um falante deseje comunicar, por mais original ou bizarra que seja a sua ideia ou a sua fantasia, a língua está em condições de satisfazê-lo”. É nessas condições de satisfazer ao falante ou à comunidade que ele pertence, que a língua se justifica como um meio de interação social e revelador da cultura, já que ela se configura no tempo e é capaz de transmitir de gerações a gerações, através de atos linguísticos, as manifestações culturais. Convém ressaltar 


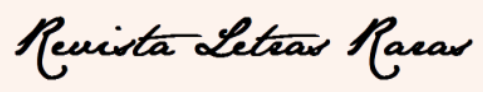

ISSN: 2317-2347 - v. 8, n. 1 (2019)

tudo que, até aqui, verificamos ser verdade a respeito das línguas, indica que se trata da obra mais notável colossal que o espírito humano jamais desenvolveu: nada menos do que uma forma completa de expressão para toda a experiência comunicável. Essa forma pode ser variada de inúmeras maneiras pelo indivíduo, sem perder com isso os seus contornos distintivos; e está constantemente remodelando-se, como sucede com toda arte. A língua é a arte mais ampla e maciça que se nos depara, cúmulo anônimo do trabalho inconsciente das gerações (SAPIR, 1980, p. 172).

Para Câmara Jr. (1955), a língua é uma parte da cultura, mas ela pode ser estudada na sua relação com a cultura ou sem considerar essa inter-relação. Segundo o autor, com essa perspectiva, o linguista se destaca do antropólogo. Porque os estudos linguísticos podem prescindir do exame da inter-relação língua e cultura, ou melhor, pode-se estudar a língua em sua imanência ou a relação da linguagem com outras áreas do conhecimento humano.

Bosi (1995) define cultura como culto e colonização, partindo da linguística, que viria do verbo latino colo, que significa eu ocupo a terra. Em outras palavras, podemos assim trazer para nosso estudo, que a cultura é a transmissão de valores e conhecimento para as próximas gerações.

Considerada a inter-relação língua e cultura, pode-se ressaltar mais uma vez que a cultura se manifesta linguisticamente, seja ela integrante de manifestações da cultura popular ou da erudita:

De modo geral, a cultura é pensada numa visão polarizante, como sendo cultura popular ou cultura erudita. Convém dizer, porém, que ambas são formas e conteúdos diferentes de expressão de uma dada realidade social e histórica. Então, não devem ser vistas como opostas ou excludentes, mas como maneiras específicas de ver, sentir e expressar a realidade conforme se situam seus atores na produção e circulação do poder (PAULA, 2007, p. 75).

Os processos culturais que são construídos por meio de atos linguísticos são uma forma identitária de dada comunidade, a qual se expressa por relações sociais como forma de conduzir e manifestar-se perante as demais comunidades, sejam elas internacionais, nacionais ou regionais. Sabemos que a cultura é a miscigenação de outras culturas. 


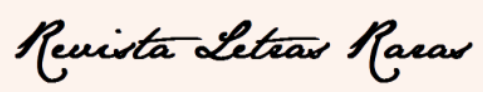

ISSN: 2317-2347 - v. 8, n. 1 (2019)

Porquanto, perceber o ato de nomeação é reconhecer que os topônimos é a interrelação de língua, cultura e ambiente, que se corporifica e com o decorrer dos tempos carrega fatores sócio-histórico-culturais de uma dada comunidade.

\section{Método e contexto, caminhos para a concretização da pesquisa toponímica}

A onomasiologia é o resultado das tendências mais significativas da evolução linguística na transição do século XIX para o século XX, em que as centralidades das investigações passam do som (fonética) para a palavra (lexicologia). O seu triunfo se deu a partir do desenvolvimento da Geografia Linguística, pois com o aparecimento de inúmeros termos regionais recolhidos pelos inquéritos linguísticos, surgiu a necessidade de um novo método, que auxiliasse os dialetólogos na compreensão do homem regional em sua amplitude por meio da linguagem.

Após a publicação dos atlas linguísticos, a onomasiologia começa a ser utilizada em vários estudos, já que, pelo seu uso, é possível caracterizar as atividades de uma região e situá-las no tempo. Segundo Couto (2012, p. 186), “a onomasiologia vê a questão da referência, para usar um termo semiótico, partindo da coisa e indo na direção do nome que ela recebe". Desta forma, "o método onomasiológico permite ver a cultura do povo cuja língua se estuda, costumes, ocupações, instrumental, crenças e crendices, moradia, enfim sua mundividência. Permite sentir a linguagem viva traduzindo a vivência cultural do povo" (BASSETO, 2001, p. 77).

O método Wörter und Sachen (Palavras e Coisas), segundo Campbell (2004), refere-se às inferências histórico-culturais que podem ser reveladas por meio da investigação das palavras, pautadas na sua analisabilidade. Campbell (2004) assume que as palavras que são analisadas em partes transparentes (vários morfemas) podem ser de criação mais recente (na língua) em relação às palavras que não apresentam essa transparência morfêmica.

A metodologia de pesquisa aqui proposta caracteriza-se por ser de natureza documental, bibliográfica e de abordagem qualitativa para o levantamento dos dados, uma vez que a constituição (sub-região, limites e fronteiras) dos "lugares" está registrada em documentos públicos e no levantamento histórico-geográfico. Os 


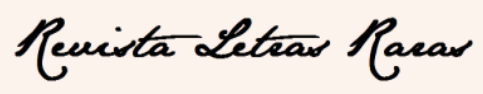

ISSN: 2317-2347 - v. 8, n. 1 (2019)

procedimentos consistem na sistematização de leituras documentais e bibliográficas, vinculados no processo da indução e segue os métodos etnolinguísticos.

O contexto desta pesquisa é o município de Pires do Rio-GO, localizado na Microrregião do Sudeste Goiano, inserida na Mesorregião Sul Goiano. A Microrregião é reconhecida como a região da Estrada de Ferro. Limita-se com os municípios goianos de Orizona, Vianópolis, Urutaí, Caldas Novas, São Miguel do Passa Quatro, Santa Cruz de Goiás, Palmelo, Cristianópolis e Ipameri. A área da unidade territorial $\left(\mathrm{km}^{2}\right)$ é de 1.073,361, com uma altitude média de 758,86.

Segundo Dias (2008), o município de Pires do Rio-GO tem como principais cursos d'água: o rio Corumbá, situado na parte sudeste; o rio Piracanjuba, no nordeste e o rio do Peixe, na parte sul, os quais correm em direção à calha do rio Paranaíba (uma das quatro bacias hidrográficas do estado de Goiás), ao sul. Os rios do Peixe e Piracanjuba desaguam no Corumbá, sendo limites de fronteiras do município. Além desses rios, a rede hidrográfica é formada por vários ribeirões e córregos.

De acordo com Silva (2017), os hidrônimos analisados na pesquisa, o léxico toponímico é carregado de marcas de expressão histórica, social, cultural, política e religiosa de dada comunidade e é representativo para o nomeador e seu grupo. Desta forma, se determinado local ou coisa passou por várias nomeações no decorrer dos tempos, isso justifica que cada nomeador observou novas características capazes de classificar ou referenciar o topônimo de forma precisa e motivada.

Para Dick (1990), as várias facetas significativas que dão realce ao nome do lugar, assim como as inúmeras informações que podem ser elencadas dele, tornariam-se um material de grande armazenamento de dados e fatos culturais em larga extensão. Assim, observamos que

os estudos toponímicos, dentro do alcance pluridisciplinar de seu objeto de estudo, constituem um caminho possível para o conhecimento do modus vivendi das comunidades linguísticas, que ocupam ou ocuparam um determinado espaço. Quando um indivíduo ou comunidade linguística atribui um nome a um acidente humano ou físico, revelam-se aí tendências sociais, políticas, religiosas, culturais (ANDRADE, 2010, p. 103).

São nessas características que residem a motivação do topônimo e por meio delas nos são reveladas história e cultura de uma dada comunidade. Por isso, os estudos 


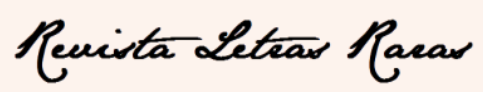

ISSN: $2317-2347$ - v. 8, n. 1 (2019)

toponímicos são de extrema relevância não só para a área dos estudos da linguagem/linguísticos, mas também para as outras áreas do conhecimento, já que o topônimo é plurissignificativo, tendo um alcance pluridisciplinar.

Posto isto, pode-se evidenciar os estudos toponímicos como um eixo norteador para se verificar as relações sócio-histórico-culturais de um povo, já que o topônimo está intimamente vinculado à cultura de uma nação e, portanto, à sua história. Desta forma, tomaremos por análise as fichas lexicográfica-toponímicas que se seguem e a taxionomia presente nos hidrônimos do município de Pires do Rio-GO.

\section{Os Zootopônimos, taxionomia dos hidrônimos do município de Pires do Rio-GO}

Os topônimos estão inseridos em duas categorias, uma de origem física e outra antropocultural, e divididos em 27 taxes. Nesta pesquisa, a origem é de natureza física e taxionomia de índole animal, zootopônimo. As fichas lexicográficas-toponímicas abaixo evidenciam em suas descrições e nos auxiliam a proceder com a análise toponímica dos designativos.

1 - Ficha lexicográfica-toponímica

$\mathrm{N}^{\mathrm{o}}$ de ordem: 01

\begin{tabular}{|l|l|}
\hline Topônimo: Rio Corumbá & Localização: Pires do Rio \\
\hline Taxionomia: Zootopônimo & Natureza: Física \\
\hline
\end{tabular}

Origem/Etimologia: cid. Mato Grosso do Sul; de corumbá, cágado. (p.44). Origem Tupi.

Estrutura morfológica: Nome Simples (Substantivo Masculino)

Informações enciclopédicas: Rio, nasce nos arredores de Pirineus, atravessa o município, como o de Santa Luzia, depois de servir, em pequeno trecho, de divisa a Bonfim. Adiante, separa Ipameri e Corumbaíba, de um lado, e Campo Formoso, Pires do Rio, Caldas Novas, Buriti Alegre, do outro, até desaguar no rio Paranaíba, pela margem direita. (M. de Corumbá).

Referências: Tibiriçá (1985), IBGE (1957).

Data da coleta: Ago./2015 a Jul./2016. 


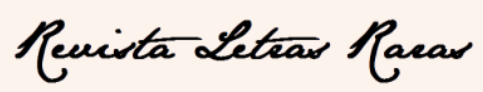

ISSN: 2317-2347 - v. 8, n. 1 (2019)

Pesquisador: Cleber Cezar da Silva.

Revisor: Prof. a Dra. Kênia Mara de Freitas Siqueira.

2 - Ficha lexicográfica-toponímica

$\mathrm{N}^{\mathrm{o}}$ de ordem: 02

\begin{tabular}{|l|l|}
\hline Topônimo: Rio do Peixe & Localização: Pires do Rio \\
\hline Taxionomia: Zootopônimo & Natureza: Física \\
\hline
\end{tabular}

Origem/Etimologia: pei-xe Sm (Zool) 1 espécime de classe animal vertebrado que nasce e vive na água, respira por guelras e se locomove por meio de barbatanas. (p.1048).

sm '(Zool.) animal cordado, gnastomado, aquático, com nadadeiras, com pele geralmente coberta de escamas, que respira por brânquias' XIII. Do lat. piscis -is \| peixADA XX \| peixARIA XX \| peixeiro \ peyxero XIII ICp. pescar, piscatório. (p.485).

Estrutura morfológica: Nome Simples (Substantivo Masculino).

Informações enciclopédicas: Rio (do), nasce na região sul-oriental do município, que separa os de Campo Formoso e Pires do Rio, entre cujo território e o de Caldas Novas, desemboca no rio Corumbá, pela margem direita. (M. de Bonfim).

Referências: Borba (2004), Cunha (2010), (IBGE (1957).

Data da coleta: Ago./2015 a Jul./2016.

Pesquisador: Cleber Cezar da Silva.

Revisor: Prof. a Dra. Kênia Mara de Freitas Siqueira.

3 - Ficha lexicográfica-toponímica

$\mathrm{N}^{\mathrm{o}}$ de ordem: 11

Topônimo: Rio Piracanjuba

Taxionomia: Zootopônimo

Localização: Pires do Rio

Natureza: Física

Origem/Etimologia: cid. de Goiás; de piracanjuba, uma var. de peixe de rio; etim.

pirá-acã-juba, peixe de cabeça amarela. (p.97). Origem Tupi.

pirá $s m$. 'designação genérica de peixe, em tupi'\| piracanjuva $s f$. 'espécie de dourado' 1792. Do tupi pirakan 'iuua (p.498).

Estrutura morfológica: Nome Simples (Substantivo Masculino). 


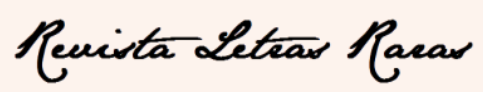

ISSN: $2317-2347$ - v. 8, n. 1 (2019)

Informações enciclopédicas: (Piracanjuba ou Paracanjuba) - Rio, nasce na serra de Passa Quatro e atravessa o município, bem como o de Pouso Alto. Adiante, separa Caldas Novas de Morrinhos e Buriti Alegre, até desaguar no rio Corumbá, pela margem direita. (M. de Bela Vista).

Referências: Tibiriçá (1985), Cunha (2010), IBGE (1957.)

Data da coleta: Ago./2015 a Jul./2016.

Pesquisador: Cleber Cezar da Silva.

Revisor: Prof. ${ }^{a}$ Dra. Kênia Mara de Freitas Siqueira.

Nas denominações de índole animal, zootopônimos, no estudo corrente, referemse aos extratos pesquisados - rio Corumbá, rio do Peixe e rio Piracanjuba. Precisamente em dois topônimos o fator motivador foi o animal peixe (Piracanjuba e Peixe) e, em outro, cágado (Corumbá), o que, possivelmente, influenciou o nomeador. A saber, a caça e pesca era o meio de sobrevivência da comunidade primitiva e o peixe é um elemento presente no cristianismo. Desta forma, possivelmente, a comunidade que habitava nos referidos locais, foi influenciada por alguma dessas razões, daí batizando os rios com os referidos hidrônimos.

Ao observarmos os topônimos de índole animal, vamos contrapor ao que Dauzat (1922, apud DICK, 1990) constatou, ter uma menor frequência dos zootopônimos em relação a outras categorias na toponímia francesa, bem como, à perspectiva de Backheuser (1952, apud DICK, 1990), de que na toponímia brasileira os nomes de animais são menos recorrentes.

A relação de denominação toponímica de uma dada região pode ser diferente de outra. Com isso, as relações de motivações estão estritamente ligadas ao nomeador, pois cada qual atribui as características inerentes ao local a que faz referência.

Conforme Dias (2008), o rio Corumbá é o maior curso d'água do município, dele se extrai areia para a construção civil e suas ilhas e margens servem para abrigar pequenas propriedades, inclusive, para a recreação e turismo. O rio do Peixe é um dos três maiores cursos d'água e fronteiriço na região sul entre Pires do Rio, Cristianópolis, Vianópolis e São Miguel do Passa Quatro, tendo como principal afluente o ribeirão Brumado, o qual é o mais importante afluente do rio Corumbá. O rio Piracanjuba também está entre os principais do município, na região norte faz fronteira entre Pires 


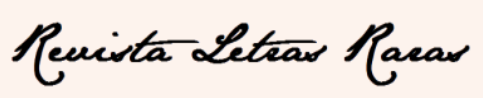

ISSN: $2317-2347$ - v. 8, n. 1 (2019)

do Rio, Orizona, Urutaí e Ipameri; sua maior relevância foi na década de 1950 por nele ter funcionado uma usina hidrelétrica que abastecia o município de Pires do Rio-GO.

A análise zootoponímica na localidade pesquisada evidenciou a valorização da fauna local, pois ao utilizar o nome de animais, recuperou-os para nomear lugares, como os rios. Observamos, que os nomes de animais, que estabelecem a sua origem nas línguas tupi (Piracanjuba e Corumbá) e latina (Peixe), motivaram a nomeação dos elementos geográficos e, de alguma forma, estão vinculados à vida do nomeador, estabelecendo relações extralinguísticas com os topônimos pesquisados. E, segundo Theodoro Sampaio (1914 apud DICK, 1990), dificilmente o nome do animal estaria desvinculado de sua existência na localidade.

O elemento de natureza física na motivação que subjaz aos topônimos, ora analisados, foram os de origem animal (peixe e cágado). Percebemos, que o nomeador teve influência das características do local para designar o referido topônimo.

\section{Considerações Finais}

Ao propormos estudar os hidrônimos do município de Pires do Rio-GO, tomamos por base caracterizar o ato de nomear e reiteramos que pode ser observado em sua totalidade a relação de poder, pois nomear é instituir. É por meio do batismo do topônimo que ele se instaura e revela as conexões do meio ambiente com o homem e/ou do homem com meio que o circunda. As considerações apresentadas referem-se aos estudos toponímicos relacionados apenas ao contexto local desta pesquisa, mas, muito ainda há de ser estudado na área, relativa à toponímia em Goiás.

A incidência de taxionomias de natureza física nesta pesquisa demonstra a tendência do denominador de nomear os lugares com nomes dos elementos físicos da natureza circundante, numa constatação de que o meio ambiente exerce grande influência sobre o homem, refletindo-se também no processo de nomeação dos lugares.

Pelo caráter motivado, o signo toponímico possibilita reconhecer fatores vinculados ao que subjaz à escolha dos nomes de lugares. O que nos possibilitou o levantamento de fatores sócio-histórico, culturais e ambientais necessários à análise 


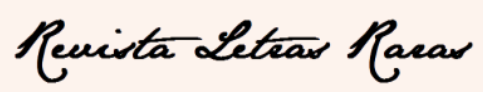

ISSN: 2317-2347 - v. 8, n. 1 (2019)

linguística dos hidrônimos e como índice de estreita relação entre língua, ambiente e cultura.

Nas taxes analisadas, foi possível detectar que o ambiente e o contexto são fundantes nas motivações aos topônimos selecionados. Desta forma, entende-se que um rio, um ribeirão, um córrego são lugares que, uma vez nomeados, passam a carregar as inúmeras memórias do lugar.

Os topônimos, além de servirem como indicadores espaciais, refletem características físicas e sociais da sociedade a que pertencem, por isso mantêm relações com os usos e costumes dessa sociedade. As relações entre língua e meio ambiente mediada por uma população no ato do batismo de um hidrônimo nos faz perceber a influência de fatores extralinguísticos e contextuais, revelados por meio da língua e cultura da população.

\section{REFERÊNCIAS}

ANDRADE, K. S. Atlas toponímico de origem indígena do estado do Tocantins: ATITO. Goiânia, GO: Ed. PUC Goiás, 2010.

AULETE, C. Dicionário escolar da língua portuguesa. Rio de Janeiro, RJ: Lexikon, 2011.

BASSETTO, B. F. Elementos de filologia românica: história, externa das línguas. São Paulo, SP: Editora da Universidade de São Paulo, 2001.

BORBA, F. S. Dicionário UNESP do português contemporâneo. São Paulo, SP: UNESP, 2004.

BOSI, A. Plural, mas não caótico. In: São Paulo, SP: Editora Ática, 1987, p. 7-15. Cultura Brasileira: temas e situações. Formações ideológicas na cultura brasileira. Estudos Avançados, 9 (25), 1995. p. 275-293. <http://www.scielo.br/pdf/ea/v9n25/v9n25a21.pdf>. Acesso em: 15 jun. 2018 .

CABRAL, J. P. Mães, pais e nomes no baixo sul (Bahia, Brasil). In: CABRAL, J. P.; VIEGAS, S. M. Nomes: género, etnicidade e família. Coimbra, PT: Almedina, 2007, p. 63-87.

CÂMARA JR., J. M. História da Linguística. Petrópolis, RJ: Editora Vozes LTDA, 1975.

Lingua e cultura. Revista Letras, 4, p. 50-59, 1955.

CAMPBELL, L. Historical Linguistics: An Introduction. Cambrige, USA: MIT, 2004. 


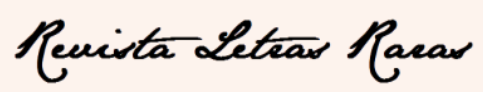

ISSN: 2317-2347 - v. 8, n. 1 (2019)

COSERIU, E. O homem e sua linguagem. São Paulo, SP: Edusp, 1982.

COUTO, H. H. Onomasiologia e semasiologia revisitadas pela ecolinguística. Revista de Estudos da Linguagem. 20(2), p. 183-210, 2012.

Ecolinguística - estudo das relações entre língua e meio ambiente. Brasília, DF: Thesaurus, 2007.

CUNHA, A. G. Dicionário etimológico da língua portuguesa. Rio de Janeiro, RJ: Lexikon, 2010.

DIAS, A. L. C. Toponímia dos antigos arraiais tocantinense. 2016. 207f. Tese (Doutoramento em Letras e Linguística). Universidade Federal de Goiânia, Faculdade de Letras. Goiânia, GO, 2016.

DIAS, C. Mapeamento do município de Pires do Rio-GO: usando técnicas de geoprocessamento. 2008. 187f. Dissertação (Mestrado em Geografia). Universidade Federal de Uberlândia. Uberlândia, MG, 2008.

DICK, M. V. P. A. Fundamentos teóricos da Toponímia. Estudo de caso: O Projeto ATEMIG - Atlas Toponímico do Estado de Minas Gerais (variante regional do Atlas Toponímico do Brasil). In: SEABRA, M. C. T. C. O léxico em estudo. Belo Horizonte, MG: Faculdade de Letras da UFMG, 2006, p. 91-117.

Rede de conhecimento e campo lexical: hidrônimos e hidrotopônimos na onomástica brasileira. In: ISQUIERDO, A. N.; KRIEGER, M. G. As ciências do léxico: lexicologia, lexicografia e terminologia. Campo Grande, MS: Editora da UFMS, 2004, p. 121-130.

O sistema onomástico: bases lexicais e terminológicas, produção e frequência. In: OLIVEIRA, A. M. P. P.; ISQUERDO, A. N. As ciências do léxico: lexicologia, lexicografia, terminologia. Campo Grande, MS: UFMS, 2001, p. 77-88.

Métodos e questões terminológicas na onomástica. Estudo de caso: o Atlas Toponímico do Estado de São Paulo. Investigações. Linguística e Teoria Literária. 9, p. 119-148, 1999.

A dinâmica dos nomes da cidade de São Paulo 1554-1987. São Paulo, SP: ANNABLUME, 1996.

Toponímia e Antroponímia no Brasil. Coletânea de Estudos. São Paulo, SP: Serviço de Artes Gráficas/FFLCH/USP, 1992.

A Motivação Toponímica e a Realidade Brasileira. São Paulo, SP: Edições Arquivo do Estado, 1990.

DUBOIS, J. Dicionário de linguística. São Paulo, SP: Cultrix, 2004.

FRAZER, J. The golden bough. Nova Iorque, USA: The MacMillan Company, 1951.

HOUAISS, A., \& VILLAR, M. S., \& FRANCO, F. M. M. Dicionário eletrônico Houaiss da língua portuguesa. Rio de Janeiro, RJ: Objetiva, 2009.

HOUAISS, A., \& VILLAR, M. S. Dicionário Houaiss da língua portuguesa. Rio de Janeiro, RJ: Objetivo, 2004. 


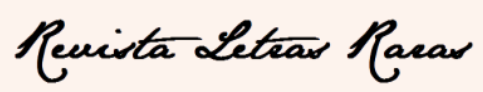

ISSN: 2317-2347 - v. 8, n. 1 (2019)

IBGE - Instituto Brasileiro de Geografia e Estatística. In: http://www.cidades.ibge.gov.br/xtras/temas.php?lang=\&codmun=521740\&idtema=16\& search=goias|pires-do-rio|sintese-das-informacoes. Acesso em: 10 set. 2017.

Enciclopédia dos Municípios Brasileiros. Rio de Janeiro, RJ: IBGE, 1957.

IMB - Instituto Mauro Borges de estatísticas e estudos socioeconômicos. In://www.imb.go.gov.br. Acessado em: 10 nov. 2017.

ISQUERDO, A. N.; SEABRA, M. C. T. C. Apontamentos sobre hidronímia e hidrotoponímia na fronteira entre Mato Grosso do Sul e Minas Gerais. In: ISQUERDO, A. N. As Ciências do Léxico: Lexicologia, Lexicografia, Terminologia. Campo Grande, MS: Ed. UFMS, 2010, p 79-98.

PAULA, M. H. Rastros de velhos falares: léxico e cultura no vernáculo catalano. 2007. 507f. Tese (Doutorado em Linguística e Língua Portuguesa). Universidade Estadual Paulista, Faculdade de Ciências e Letras. Araraquara, SP, 2007.

PEREIRA, R. R. A toponímia de Goiás: em busca da descrição de nomes de lugares de municípios do sul goiano. 2009. 2014f. Dissertação (Mestrado em Estudos da Linguagem). Universidade Federal do Mato Grosso do Sul, Centro de Ciências Humanas e Sociais. Campo Grande, MS, 2009.

SAMPAIO, T. O Tupi na geografia nacional. Salvador, BA: Secção Graphica da Escola de Aprendizes Artificies, 1928.

O Tupi na Geographia Nacional. Memória lida no Instituto Histórico e Geographico de São Paulo. São Paulo, SP: Typ. da Casa Eclectica, 1901.

SAPIR, E. A Linguagem. São Paulo, SP: Perspectiva, 1980.

Linguística como ciência. Rio de Janeiro, RJ: Livraria Acadêmica, 1969.

SAUSSURE, F. Curso de Linguística Geral. São Paulo, SP: Cultrix, 2008.

SIQUEIRA, K. M. F. O léxico tupi na nomeação dos lugares goianos nos séculos XVII e XVIII. In: PAULA, M. H. (Org.). Língua e Cultura: estudos de léxico em perspectiva. Goiânia, GO: Ed. UFG, 2015. p. 85-104.

Toponímia Kalunga: aspectos da inter-relação língua, povo e território. Via Litterae, 7(1), p. 61-75, 2015.

(2012). Nos trilhos da estrada de ferro: reminiscências de motivações toponímicas. Revista da ANPOLL, 1(32) p. 150-170, 2012.

SILVA, A. M. Dossiê de Goiás - Enciclopédia Regional: um compêndio de informações sobre Goiás, sua história e sua gente. Rio de Janeiro: Sindicato Nacional dos Editores de Livros, 2001.

SILVA, A. S. Palavras, significados e conceitos o significado lexical na mente, na cultura e na sociedade. Cadernos de Letras da UFF. Dossiê Letras e cognição, 41, p. 27-53, 2010.

SILVA. C. C. Os cursos d'água de Pires do Rio: análise das motivações toponímicas. 2017. 122f. Dissertação (Mestrado em Estudos da Linguagem). Universidade Federal de Goiás, Unidade Acadêmica Especial de Letras e Linguística. Catalão, 2017. 


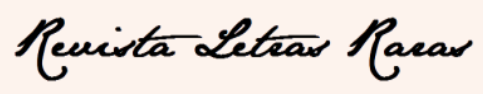

ISSN: 2317-2347 - v. 8, n. 1 (2019)

SILVA, T. T. Identidade e Diferença: a perspectiva dos estudos culturais. Petrópolis, RJ: Vozes, 2000.

TIBIRIÇA, L. C. Dicionário de topônimos brasileiros de origem tupi. Santos, SP: Traço Editora, 1985.

WHORF, B. L. Lenguage, Pensamiento y Realidad. Barcelona-Espanha: Barral Editores, 1971.

Recebido em: 12/07/2018

Aceito em: 06/02/2019 